\title{
The costs of integrating reproductive health services: An example using syndromic management of STIs in family planning clinics in Zimbabwe
}

Baker Ndugga Maggwa

Ian Askew

Population Council

Caroline S. Marangwanda

Barbara Janowitz

Laura Johnson

See next page for additional authors

Follow this and additional works at: https://knowledgecommons.popcouncil.org/departments_sbsr-rh

Part of the Demography, Population, and Ecology Commons, and the International Public Health Commons

How does access to this work benefit you? Let us know!

\section{Recommended Citation}

Maggwa, Baker Ndugga, Ian Askew, Caroline S. Marangwanda, Barbara Janowitz, Laura Johnson, Andrew Thompson, and Caroline West. 1999. "The costs of integrating reproductive health services: An example using syndromic management of STIs in family planning clinics in Zimbabwe," Africa OR/TA Project II. Harare: Population Council, Zimbabwe National Family Planning Council, and Family Health International. 


\section{Authors}

Baker Ndugga Maggwa, Ian Askew, Caroline S. Marangwanda, Barbara Janowitz, Laura Johnson, Andrew Thompson, and Caroline West 


\title{
The Costs of Integrating Reproductive Health Services: An Example Using Syndromic Management of STIs in Family Planning Clinics in Zimbabwe
}

\author{
Ndugga Maggwa \\ Ian Askew \\ The Population Council \\ Caroline Marangwanda \\ Zimbabwe National Family Planning Council \\ Barbara Janowitz \\ Laura Johnson \\ Andy Thompson \\ Caroline West \\ Family Health International
}


Introduction

There is a great deal of interest in the costs associated with reproductive health care. Estimates prepared by the United Nations Population Fund (UNFPA) indicate that the costs of family planning and other reproductive health services are increasing and that it will be difficult for donors and countries to meet these costs. (UNFPA 1997) .

There is no uniformly accepted methodology for determining the costs of reproductive health. For example, a recent study by Mitchell et. al. (1999) provided data on the costs of adding various reproductive health services to family planning programs in Zimbabwe and Mexico. The study took into consideration the costs of personnel, materials and pharmaceuticals; however, it ignored infrastructure costs. The authors argued that "many institutions delivering reproductive health services operate significantly below their physical capacity to see clients, and that much of the equipment required for expanding reproductive health services may already be available for use....” Consequently, they argue that the marginal costs of adding infrastructure would be low.

A parallel argument can be made regarding labor costs. Many institutions have staff that are not fully occupied, and thus the staff necessary to expand reproductive health services may also be in place. In such a case, the incremental labor costs of adding reproductive health services will be low as additional staff will not be needed to expand service provision. In fact, some previous research indicates that staff in some clinics have unused time that could be reallocated to provide additional services. (See, for example, Janowitz et al (1997) and Hubacher et al (1999).) Because labor is the most important component of costs, it is particularly important to determine how clinic staff spend their time in order to ascertain whether additional staff time is needed to expand service provision.

The wage bill will not change if no new staff are hired to provide additional services. However, if new tasks turn out to take up a large amount of time, clinics may need to hire additional workers and monetary costs will be higher. Even if new workers are not hired, there may be opportunity costs. If staff are very busy, then adding a new service during visits will take time away from the provision of existing services, so that the number of visits and the service provided in these visits may decline. If, however, staff has unoccupied time, and new services can be provided by using some of that time, 
then no costs for additional labor, financial or otherwise, need be incurred. Consequently the costs of providing reproductive health care would be lower than implied either by the aggregate estimates of UNFPA or the estimates that would be obtained through aggregation of average costs from micro level studies conducted at service delivery points.

In this paper, we examine the cost implications for labor of expanding the provision of syndromic management services in family planning clinics in Zimbabwe. Syndromic management of sexually transmitted infections (STIs) allows health care workers to make a diagnosis without sophisticated laboratory tests because it is based on clinical syndromes and, in some cases, assessments of an individual patient's risk for STI infection. (Hoffman et al 1997).

\section{Data and Methods}

As applied in Zimbabwe, the syndromic approach included a risk assessment that included information on behavior and signs and symptoms, and a pelvic exam to check for signs. All new family planning acceptors, clients coming in for a one-year check-up, and some clients coming in for “other reasons” were targeted to receive the syndromic approach. Providers had been previously trained in syndromic management but there were concerns that providers had not implemented it, so providers were retrained in the approach. Finally, to test the accuracy of the approach (sensitivity, specificity and positive predictive value), specimens were collected for laboratory testing.

In order to determine whether labor costs should be taken into consideration in determining the costs of the syndromic approach, we asked two questions: First, how much did the length of visits increase following retraining in the syndromic approach? Second, did providers have unoccupied time that could be drawn on to provide these services or did they have to reduce time spent on other services provided to clients?

Baseline information was obtained in January and February 1998, at two family planning clinics. Three clinics were included in the post-test in May and June 1998, including the two from the pre-test and an additional clinic in which retraining was conducted. 
Information on the duration of contact time and the various activities carried out in different types of family planning visits was obtained by observing visits prior to and following the retraining of providers in syndromic management. Observers completed a pre-coded form for the visits that they observed. The form contained information on whether or not a risk assessment was carried out, and if so, how many items of the risk assessment were completed; ${ }^{1}$ whether a pelvic exam was done; and whether specimens were collected for the lab tests to validate the syndromic approach. In addition, other information regarding the visit was obtained including data on family planning services provided, other clinical exams carried out, and other discussions held.

Data were also obtained to determine whether providers had sufficient time to provide new STI services. Providers were interviewed every day at the end of each day for a week before and for a week after the retraining to determine if the retraining led to a change in how they allocated their time. They were questioned about how much time they spent with clients including the number and duration of different types of visits, and how they spent their time when they were not with clients. Because of concerns with the validity of the results obtained from the interviews, we also conducted a time-motion study following retraining to get objective data on how providers spent their time during a full day. Observers recorded information on how providers spent their days including direct service provision time with clients, time spent on activities supporting visits and other administrative tasks, and time spent on other than work-related activities. Observers used a stopwatch that "beeped" every five minutes. At the beep, the observer noted the activity being performed. In the analysis, each noted activity was then multiplied by 5 and summed across the different activities. However, the time motion study was only carried out subsequent to the retraining.

In order to evaluate the impact of implementing the syndromic approach, mean visit lengths for each service received were compared. Because of the small numbers of cases, Mann-Whitney Wilcoxon tests were used to measure the significance of the differences in means. We determined whether the staff could incorporate the new STI activities into their workload by examining activities that were carried out after the retraining in syndromic management. In addition, we determined a hypothetical

\footnotetext{
${ }^{1}$ Items in the risk assessment included if the provider asked: if the client had more than one partner in the past 12 months; if the client had any concerns about STDs or HIV/AIDS; if the client had previous symptoms, signs, or treatments; if the client's partner had previous signs, symptoms, or treatments; and if the client lives away from regular partner.
} 
workload for staff under the assumption that those clients that were targeted to receive syndromic management actually received it. We then calculated the time necessary to carry out these new activities.

Several months after the time motion study had been carried out, we collected additional data to estimate the average costs of providing different types of visits for reproductive health services, including family planning. In order to accomplish that objective, we obtained information on the salaries and benefits of clinic providers and support staff, on the costs of gloves (the main materials cost for visits), on the rental cost of buildings, and on the costs of capital goods. We also obtained information on the use of other supplies, but these data varied so much among clinics that we decided not to use this information. Finally information on the costs of contraceptives was obtained from a recent study on the costs of commodities and materials to provide reproductive health services.

While the product produced by the clinic is a visit of a particular type, staff are paid not only for the time that they spend on direct care provided in visits, but also for time spent on other indirect care to support visits, other administrative work and for time spent on non-work related activities. We calculate the labor cost per visit using actual data on how staff spend their time, and under various scenarios in which the amount of time that staff spend with clients varies. Mean visit lengths for different types of family planning services were used in the calculations.

Results

\section{$\underline{\text { Length of visits }}$}

The median length of visits for new acceptors was longer in the post than in the pre-test for the two clinics for which data were available for both time periods (27 vs. 20 minutes). However, post-test visits at Lister were similar in length to those found in the clinics included in the pre-test (20 minutes). These results would indicate that the syndromic approach was more fully implemented in the former two clinics than at Lister. ${ }^{2}$

\footnotetext{
${ }^{2}$ Other comparisons are not easily made because of different sampling strategies used in the pre and post-test. The pretest group likely includes a high percentage of women coming for a one-year check-up while the post-test group simply reflects the general population of women coming for re-supply. This latter group probably includes a high percentage of women not scheduled to receive a one-year check-up.
} 


\section{$\underline{\text { Services received }}$}

Visit length may have increased in the post-test because a higher percentage of women received any of the services covered either in the retraining or necessary to validate the syndromic approach: risk assessment, a pelvic exam, or collection of lab specimens. Table 1 shows the percent of new family planning acceptors who received these specific services in the pre and post-tests. The percentage of new acceptors who received the risk assessment did increase (from 14 to 40 percent), as did the percent that received a pelvic exam.

However, the percentage of new acceptors who received some of the services was about the same or lower at Lister than at clinics in the pre-test group. This lack of difference may explain why visit lengths were similar at Lister to those found in the pre-test group.

Table 1. Percent of New FP Acceptors Who Received Specific Services

\begin{tabular}{|l|c|c|c|}
\hline & Pre & \multicolumn{2}{|c|}{ Post } \\
\cline { 2 - 4 } \multicolumn{1}{|c|}{ Type of Service } & $\begin{array}{c}\text { Spilhaus and } \\
\text { Mpilo } \\
\text { (n=14) }\end{array}$ & $\begin{array}{c}\text { Spilhaus and } \\
\text { Mpilo } \\
\text { (n=20) }\end{array}$ & $\begin{array}{c}\text { Lister } \\
\text { (n=13) }\end{array}$ \\
\hline Risk Assessment & 14 & 40 & 23 \\
$\begin{array}{l}\text { Mean number of items in risk } \\
\text { assessment }\end{array}$ & 2 & 3 & 3 \\
\hline Pelvic Examination & 50 & 70 & 31 \\
\hline Specimens for STD lab tests & 0 & 30 & 8 \\
\hline
\end{tabular}

Visit length and services received

Table 2 explores the various factors that contribute to the length of a visit including risk assessment, a pelvic exam and the collection of lab specimens. Because some of the cell sizes are small, we also show the median visit length. 
Table 2. Mean and Median Contact Time by Services Provided, for New FP Acceptors and Resupply/Repeat FP Clients for Post-Test

\begin{tabular}{|l|c|c|c|c|c|c|}
\hline & \multicolumn{3}{|c|}{ Risk Assessment } & \multicolumn{3}{c|}{ No Risk Assessment } \\
\hline Lab Tests & Yes & No & No & Yes & No & No \\
\hline Pelvic Exam & Yes & Yes & No & Yes & Yes & No \\
\hline Duration of Visit & & & & & & \\
(in Minutes) & 43 & 26 & 10 & 58 & 26 & 10 \\
Mean & 43 & 25 & 10 & 38 & 22 & 8 \\
Median & $(23)$ & $(7)$ & $(9)$ & $(3)$ & $(18)$ & $(127)$ \\
(n)
\end{tabular}

Note: Mann-Whitney Wilcoxon Test to test significance of difference of means: Risk Assessment/Lab Tests/Pelvic Exam v. Risk Assessment/No Lab Tests/Pelvic Exam: sig $=.002$ Risk Assessment/No Lab Tests/Pelvic Exam v. Risk Assessment/No Lab Tests/No Pelvic Exam: sig $=.004$ No Risk Assessment/Lab Tests/Pelvic Exam v. No Risk Assessment/No Lab Tests/Pelvic Exam: sig = .034 No Risk Assessment/No Lab Tests/Pelvic Exam v. No Risk Assessment/No Lab Tests/No Pelvic Exam: sig $=.000$

Women whose risk was assessed but who did not receive any of the two other services spent about the same amount of time with a provider as did women who received none of these services. It would appear that conducting a risk assessment adds little or no time to a visit.

A pelvic exam adds about 15 minutes to the length of a visit, and this increase in visit length is not dependent on whether a woman had a risk assessment. The collection of lab specimens adds about 17 minutes to the visit for those women who had both a pelvic exam and a risk assessment.

We may conclude that if syndromic management (or a pelvic examination) were to become a routine part of family planning visits for selected groups of women, it would add about 15 minutes to their visits. Risk assessment added no time and the lab specimens were collected for validation purposes only and would not be carried out once the study concluded.

Estimated contact time needed to routinely provide the syndromic approach An interesting question is the following: what would be the increase in the total time that providers spent on visits if the syndromic approach was introduced for a group of targeted clients. For Spilhaus, 
given an average contact time of 22.7 minutes per visit and an average of 9.5 visits, ${ }^{3}$ the current average time spent per day with clients is now about 217 minutes (Table 3). All new FP acceptors, clients coming in for a one-year FP check-up, and some clients coming in for "other reasons" would be targeted to receive the syndromic approach. Assuming that one-third of revisits occurred at one year and that half of the women in the "other" group were targeted for the syndromic approach, we calculate that about half of women coming in for visits would need to be targeted. No changes are expected to occur in other visit groups. For example, at Spilhaus, the number of clients that receive syndromic management increases by 0.4 per day [(.47-.41)(6.3)]. These visits require an additional 6.1 minutes per day $(0.4 \times 16)$. However, lab test verification would end thereby reducing visit time by 17 minutes in the 21 percent of targeted clients for whom specimens were collected $(.21 \times 6.3 \times 17)$ or by a total of 22 minutes. The total time with clients would decrease to 201 minutes if all of the targeted clients received syndromic management, but lab specimens were not obtained. Results are similar for Mpilo. At Lister, total time with clients would increase by about 35 minutes to 196 minutes per provider per day, if they were to do syndromic management.

\footnotetext{
${ }^{3}$ This figure was adjusted upward to account for the possible underreporting of observed visits. The correction took into consideration estimated contact time from the time motion study. See Table 3 and the following section.
} 
Table 3. Potential Impact of Implementing Syndromic Management on Time Spent with Clients

\begin{tabular}{|c|c|c|c|}
\hline & Spilhaus & Mpilo & Lister \\
\hline Average number of visits per provider per day & 7.1 visits & 10.7 visits & 5.5 visits \\
\hline Adjusted average number of visits per provider per day ${ }^{1}$ & 9.5 visits & 11.8 visits & 8.5 visits \\
\hline Average length of visits & 22.7 minutes & 17.0 minutes & 19.1 minutes \\
\hline Average daily contact time per provider per day ${ }^{2}$ & 217.1 minutes & 199.7 minutes & 161.7 minutes \\
\hline $\begin{array}{l}\text { Average number of visits per provider per day for FP acceptors, } \\
\text { repeat visits, or "other”3 }\end{array}$ & 6.3 & 10.5 & 6.8 \\
\hline $\begin{array}{l}\text { Percent of these clients who should receive syndromic } \\
\text { management }{ }^{4}\end{array}$ & $47 \%$ & $43 \%$ & $58 \%$ \\
\hline Percent of these clients who did receive syndromic mangement ${ }^{5}$ & $41 \%$ & $32 \%$ & $18 \%$ \\
\hline $\begin{array}{l}\text { Added time to offer syndromic management for "targeted" } \\
\text { clients }{ }^{6}\end{array}$ & 6.1 minutes & 18.6 minutes & +43.2 minutes \\
\hline Subtracted time for lab tests ${ }^{7}$ & -22.1 minutes & -30.6 minutes & -8.5 minutes \\
\hline Net change in daily contact time per provider & -16 minutes & -12 minutes & + 34.7 minutes \\
\hline $\begin{array}{l}\text { Average daily contact time per provider if syndromic } \\
\text { management implemented }\end{array}$ & 201.1 minutes & 187.7 minutes & 196.4 minutes \\
\hline $\begin{array}{l}\text { The adjusted number of visits was calculated by dividing the average total con } \\
\text { average visit length in the mini situation analysis (MSA). } \\
\text { Average daily contact time }=\text { adjusted average number of visits x average leng } \\
\text { For Spilhaus, new FP acceptors, repeat FP visits, and "other" visits made up } 6 \\
89 \% \text { and } 80 \% \text { of the total visits, respectively. } \\
\text { Based on the assumption that all new FP acceptors, one-third of repeat FP clie } \\
\text { management. } \\
\text { Based on the percent of these clients who received pelvic examinations. } \\
\text { Calculation: For Spilhaus: } 6 \% \text { of } 6.3 \text { visits }=0.38 \text {. Time needed to perform p } \\
\text { minutes. For Mpilo: } 11 \% \text { of } 10.5 \text { visits }=1.16 \text {. Time needed to perform pelvi } \\
\text { minutes. For Lister: } 40 \% \text { of } 8.3 \text { visits }=2.7 \text { visits. } 2.7 \text { visits x } 16 \text { minutes }=4 \\
\text { Lab tests were performed for verification. Calculation: For Spilhaus: } 21 \% \text { of } \\
\text { Time needed for specimen collection }=17 \text { minutes. } 1.3 \text { visits x } 17 \text { minutes }= \\
\text { collected. } 17 \% \text { of } 10.5 \text { visits }=1.8 \text {. Time needed for specimen collection }=17 \\
\text { "targeted" clients had specimens collected. } 7 \% \text { of } 6.8 \text { visits }=0.5 \text {. Time need } \\
8.5 \text { minutes. }\end{array}$ & $\begin{array}{l}\text { ot time from the TM } \\
\text { of visits. } \\
6 \text { of the total visits. } \\
\text {, and half of "other" } \\
\text { ic examination = } 16 \\
2 \text { minutes. } \\
\text { argeted" clients had } \\
1 \text { minutes. For Mpi } \\
\text { hinutes. } 1.8 \text { visits } x \\
\text { for specimen collect }\end{array}$ & $\begin{array}{l}\text { or Mpilo and Lister, } \\
\text { clients should receiv } \\
\text { minutes. } 0.38 \text { visits } \\
\text { nutes. } 1.16 \text { visits x } 1 \\
\text { specimens collected. } \\
\text { lo: } 17 \% \text { of "targeted" } \\
17 \text { minutes }=30.6 \mathrm{mi} \\
\text { ion }=17 \text { minutes. } 0 .\end{array}$ & $\begin{array}{l}\text { these clients made up } \\
\text { syndromic } \\
\text { x } 16 \text { minutes = } 6.1 \\
\text { minutes = } 18.6 \\
21 \% \text { of } 6.3 \text { visits = } 1.3 \text {. } \\
\text { clients had specimens } \\
\text { nutes. For Lister: } 7 \% \text { of } \\
\text { visits x } 17 \text { minutes = }\end{array}$ \\
\hline
\end{tabular}

\section{Impact of syndromic management on provision of other services}

An important question is whether staff can provide syndromic management without reducing the current number of visits or taking time away from other services performed during a visit. We use the data from the time motion study to address this question. As mentioned previously, such 
information is available only for the post-test period; unfortunately, the provider interviews, which were conducted pre and post-test, did not prove to be reliable, and could not be used.

Figure 1 shows for the three clinics how time spent in different activities varies over the course of the day. The percent of time spent in direct care activities increases throughout the morning, with the maximum percent of time spent in direct care activities at 56 percent occurring between 11 a.m. and noon. The percent of time spent on lunch and tea breaks is highest from 10 to 11 a.m. and from 1 to 2 p.m. Time spent unoccupied is highest in the early morning hours (or staff have simply not arrived) or in the late afternoon hours.

\section{Figure 1. Activities by Hour}

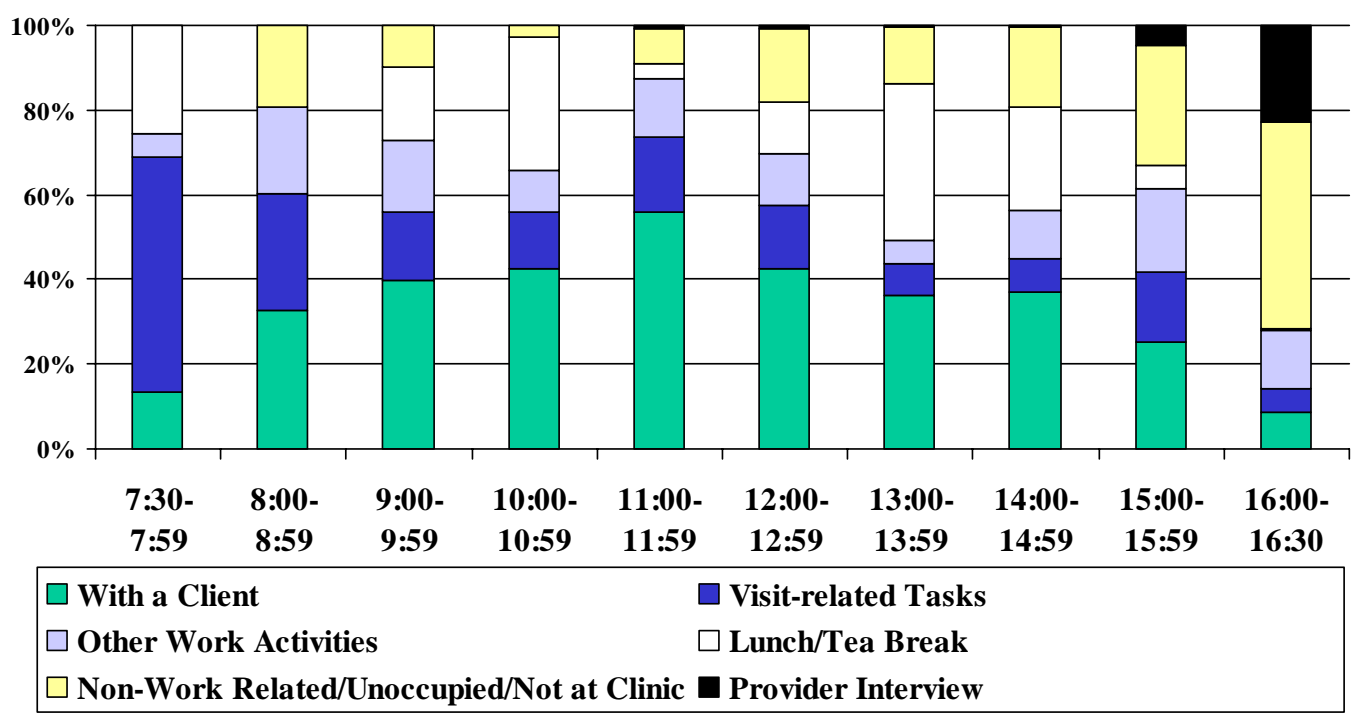

Visit-related tasks include: completing/reviewing forms, filing forms, preparation of workspace, and preparing for next client. Other work activities include: work-related discussion with staff, official meeting,reading, and phone call.

Time motion study based on observations over a 5-day period of three providers at each clinic.

Spilhaus and Lister open at 8:00 and close at 4:30; Mpilo opens at 7:30 and closes at 4:00. Thus, the first bar refers only to Mpilo while the last bar refers only to Spilhaus and Lister..

Figure 2 shows the percent of time spent on various activities for the full day, for each of the clinics and for the aggregated group of clinics. Table 4 shows the average time spent in minutes per day on various activities. For all clinics, about 38 percent of time was spent with clients with an additional 29 percent spent in various administrative tasks or other work activities. The percent of time spent 
with clients was higher at Spilhaus and Mpilo than at Lister. ${ }^{4}$ Thus, time spent with clients in the post-test was higher for the two clinics that had more fully implemented the syndromic approach and had also collected lab samples.

\section{Figure 2. Percent Distribution of Staff Time by Activity}

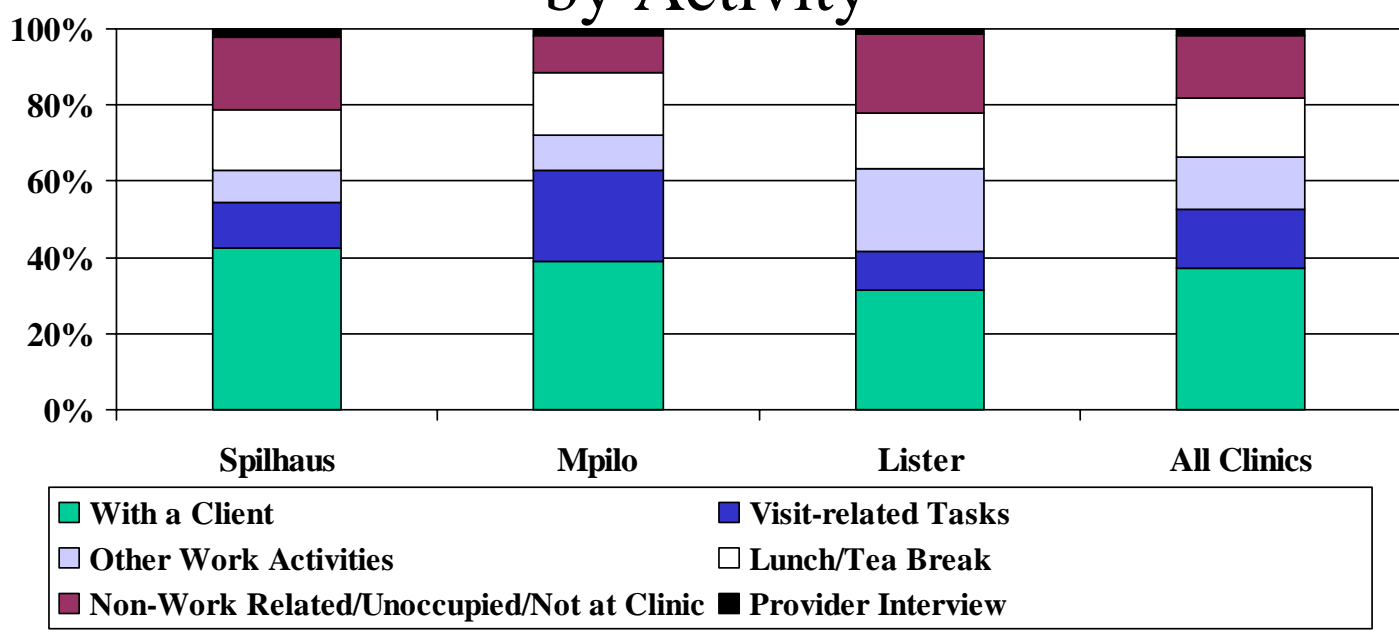

Administrative tasks include: completing/reviewing forms, filing forms, preparation of workspace, and preparing for next client. Other work activities include: work-related discussion with staff, official meeting,reading, and phone call.

Time motion study based on observations over a 5-day period of three providers at each clinic.

\footnotetext{
${ }^{4}$ One reason for the difference is that Spilhaus and Mpilo are drop-in clinics whereas clients at Lister schedule
} appointments. 
Table 4. Average Daily Staff Time Spent on Activities (In Minutes)

\begin{tabular}{|l|c|c|c|c|}
\hline Activity & Spilhaus & Mpilo & Lister & All Clinics \\
\hline With a client & 217 & 200 & 162 & 192 \\
\hline Visit-related tasks & 63 & 123 & 51 & 80 \\
\hline Other work activities & 43 & 49 & 113 & 70 \\
\hline Lunch/tea break & 81 & 83 & 75 & 79 \\
\hline $\begin{array}{l}\text { Non-work related/ } \\
\text { unoccupied/not at clinic }\end{array}$ & 94 & 46 & 102 & 80 \\
\hline Provider interview & 12 & 9 & 7 & 9 \\
\hline Total & 510 & 510 & 510 & 510 \\
\hline
\end{tabular}

Administrative tasks include: completing/reviewing forms, filing forms, preparation of workspace, and preparing for next client.

Other work activities include: work-related discussion with staff, official meeting, reading, and phone call.

\section{Discussion}

Our results indicate that no additional labor was needed to provide syndromic management for the three clinics included in this study. Thus, no additional costs are incurred for labor, and its marginal cost is zero. Our calculations show that a more widespread adoption of the syndromic approach can be achieved without increasing the number of providers, or reducing other services provided in visits. Whether clinics think that the benefit of time spent in providing syndromic treatment is worth the cost is a separate issue and has been widely discussed elsewhere (Marrazo,1997).

An important limitation of our study is that we are unable to definitively say that the retraining and reinforcement in the syndromic approach combined with the collection of lab specimens did not affect the quantity and quality of other services provided during visits. Our findings, however, 
indicate that such a result is unlikely. While visits were substantially longer for women who had pelvic exams or lab specimens collected, and total time spent with clients undoubtedly increased, our calculations indicate that providers still had substantial amounts of time that could be used to expand service provision. Providers have some unoccupied time at work, and some time when they are simply not at the clinic. There is also a substantial amount of time devoted to supporting work. In all three clinics, about as much time is spent with clients as on these other tasks. Even though additional time is required to clean and prepare instruments for pelvic exams and to obtain lab specimens, it appears that there is more than ample time available to accomplish these tasks. Therefore, any time required to perform syndromic management could have been drawn from unused time, or work time used for supporting activities.

We therefore argue that it is not sufficient to estimate the added labor costs needed to provide a new service simply by measuring how much additional staff time is necessary for that service. Many family planning clinics in the developing world operate under conditions similar to the three in Zimbabwe, in which there is a fairly high percentage of time during the day when providers are not directly engaged in client related activities. Because the average cost of providing a service is dependent on how staff use their time, an increase in the percentage of time spent in visits will reduce the per unit cost of visits.

Our findings have implications beyond the cost of providing syndromic management to family planning clients. Other efforts to measure the costs of integrating family planning and reproductive health programs can also benefit from our examination of labor costs. Many of these estimates of adding new services to existing programs assume a multiplicative relationship between the number of 
visits and costs, and do not take into consideration the way that staff spend their time. Consequently, these estimates are likely too high. Instead, cost studies of service integration should determine whether staff can add new services or visits without a negative impact on the current provision of visits. Realizing these results will require an increase in the efficiency of the production of health services, and a corresponding improvement in clinic management. Given the resource constraints facing most reproductive health programs, however, these changes are necessary if programs are to expand the quality and variety of services that they provide. 
References

Janowitz B, Holtman M, Hubacher D, and Jamil K. “Can the Bangladeshi Family Planning Program Meet Rising Needs Without Raising Costs?” International Family Planning Perspectives 23(3): 116121, 1997.

Hoffman, Irving and Bea Vuylsteke “STD Syndromic Management.” Series Editor: M. Ricardo Calderon. Arlington: AIDSCAP, 1997.

Hubacher D, Holtman M, Fuentes M, Perez-Palacios G, Janowitz B. Increasing efficiency to accommodate future demand: family planning services at the Mexican Ministry of Health. Forthcoming in International Family Planning Perspectives, 1999.

Marrazo JM, Celum CL, Hillis SD, et al. Performance and cost effectiveness screening criteria for chlamydia trachonmatis infection in women: Implication for a national screening control strategy. STD 1997; 3: 131-141.

Mitchell MD, Littlefield J and Gutter S. “Costing of Reproductive Health Services.” International Family Planning Perspectives 25 Supplement: S17-S21, 1999.

UNFPA. Global Population Assistance Report, 1995. New York: UNFPA 1997. 